\title{
PERIVENOUS SUPPORT REDUCES EARLY CHANGES IN HUMAN VEIN GRAFTS: STUDIES IN WHOLE BLOOD PERFUSED HUMAN VEIN SEGMENTS
}

W. Stooker, MD

H. W. M. Niessen, $\mathrm{PhD}^{\mathrm{b}}$

A. Baidoshvili ${ }^{b}$

W. R. Wildevuur ${ }^{\mathrm{c}}$

V. W. M. Van Hinsbergh, $\mathrm{PhD}^{\mathrm{d}, \mathrm{f}}$

J. Fritz

C. R. H. Wildevuur, $\mathrm{PhD}^{\mathrm{e}}$

L. Eijsman, $\mathrm{PhD}^{\mathrm{a}}$
Background: Patency of vein grafts in coronary artery bypass grafting procedures is generally less favorable than those of selected arterial grafts. However, vein grafts still are needed in cardiac operations. It would be desirable to find measures to improve the patency of vein grafts next to antithrombotic regimens. Animal studies demonstrated that arterial pressure induces overdistention of the thin-walled vein grafts and that prevention of this overdistention with extravascular support ameliorates the arterialization process with, subsequently, more favorable patency. To evaluate whether perivenous stenting of the rather muscular human vein grafts is also beneficial, we designed an in vitro model to study the early effects of perivenous support in human vein grafts.

Methods: Seven paired segments of human vein graft obtained during coronary artery bypass grafting procedures were placed in a perfusion circuit and perfused simultaneously with autologous whole blood, with a pressure of 60 $\mathrm{mm} \mathrm{Hg}$ (nonpulsatile flow). After 30 minutes of perfusion, one segment, and after 60 minutes of perfusion, the remaining segment were taken for histologic and immunohistochemical examination. In the next experiments $7 \mathrm{seg}$ ments of human vein graft were placed in the circuit and supported with a polytetrafluoroethylene graft to prevent overdistention with 7 unstented segments as controls.

Results: In unsupported vein grafts perfused with autologous blood under a pressure of $60 \mathrm{~mm} \mathrm{Hg}$, a complete de-endothelialization was shown after 1 hour of perfusion. In the study vein grafts, with a perivenous polytetrafluoroethylene graft preventing overdistention $(n=7)$, the endothelium remained intact. Electron microscopic investigation of the media showed severe damage in the circular smooth muscle layer in the unstented group, whereas in the stented group almost no injury was found.

Conclusion: In our in vitro closed-loop model, reproducible vessel wall changes were observed in all human vein graft specimens studied. The beneficial effect of perivenous support could also be established for the human greater saphenous vein, providing a basis for clinical application. ( $\mathrm{J}$ Thorac Cardiovasc Surg 2001;121:290-7)
$\mathrm{T}^{\mathrm{h}}$ he patency rates of human vein grafts after coronary artery bypass grafting are less favorable than those of selected arterial grafts, 1,2 although the results of follow-up studies remain unequivocal. ${ }^{3-5}$ Despite the

From the Department of Cardiac Surgery, ${ }^{\mathrm{a}}$ Institute of Pathology, Department of Extra Corporeal Circulation, ${ }^{\mathrm{c}}$ and Institute for Cardiovascular Research, " "Vrije Universiteit," Amsterdam; Gaubius Laboratory, ${ }^{\mathrm{e}}$ TNO-PG, Leiden; and the Department of Experimental Thoracic Surgery, ${ }^{\mathrm{f}}$ University of Groningen, The Netherlands.

Dr Niessen is a recipient of the Dr Dekker program of the Netherlands Heart Foundation.

Received for publication April 28, 2000; revisions requested June 14, 2000; revisions received July 25, 2000; accepted for publication Sept 15, 2000. increased use of arteries as a bypass graft (eg, thoracic arteries, gastroepiploic artery, and radial artery), ${ }^{6,7}$ vein grafts still are necessary in most patients, although they are prone to less favorable patency rates.

Address for reprints: W. Stooker, MD, Department of Cardiac Surgery L-325, University Hospital "Vrije Universiteit," PO Box 7057, 1007 MB Amsterdam, The Netherlands (E-mail: w.stooker@azvu.nl).

Copyright () 2001 by The American Association for Thoracic Surgery

$0022-5223 / 2001 \$ 35.00+0 \quad \mathbf{1 2 / 1 / 1 1 1 6 5 6}$

doi:10.1067/mtc.2001.111656 
Many efforts have been made to improve the graft patency. Antithrombotic regimens in particular have been thoroughly investigated, ${ }^{8}$ showing superior patency in patients receiving acetylsalicylic acid.

In different animal models (sheep, ${ }^{9}$ rabbit, ${ }^{10,11}$ and pig ${ }^{12,13}$ ) graft patency could successfully be improved by perivenous stenting of vein grafts placed in the arterial circulation. These studies emphasized that, among various other factors (preoperative structural and functional status of the vein graft, surgical technical aspects, ischemic injury, and composition of storage media), overdistention of the vein graft by the arterial pressure is the principal cause promoting intimal hyperplasia and vein graft atherosclerosis. ${ }^{14-20}$ The hypothesis is that by simply preventing overdistention of the vein graft wall with an external jacket or stent, the vein is protected against the destructive effect of the sudden exposure to arterial pressure. As a consequence, the process of structural adaptation to the arterial pressure, arterialization, proceeds more evenly.

The acute changes and structural damage in human vein grafts is difficult to study systematically. In postmortem studies Kockx and associates ${ }^{21}$ described the acute histopathologic changes in human saphenous vein grafts in the first week after coronary artery bypass grafting. They found a significant loss of endothelial cells, damage to medial smooth muscle cells, and leukocyte infiltration of the vein graft wall. This is in accordance with the animal studies. ${ }^{10,22}$

Here we report the early effect of nonpulsatile perfusion of human vein segments in vitro with autologous whole blood and with arterial pressure. We describe the pathologic findings in the vein wall and the effect of perivenous stenting during the first hour of perfusion.

\section{Methods}

Patients were included in the study after providing informed consent. The study was approved by the local ethics committee (January 28, 1998). Anesthesia and cardiopulmonary bypass were performed according to the routine protocol.

In the in vitro model we use a small roller pump (Stöckert Instrumente, Munich, Germany) with a vein irrigation set (Bentley Laboratories Europe, Uden, The Netherlands). In the perfusion circuit two pieces of vein graft, one externally supported with a polytetrafluoroethylene (PTFE) graft and one without, can be perfused with nonpulsatile flow under the same pressure the vein graft encounters in the first hour after completion of the proximal anastomosis, as well as being exposed to comparable circulatory conditions. A Haemonetics bag (Haemonetics Corporation, Braintree, Mass) is used as a fluid reservoir in this experiment and filled with oxygenated blood from the heart-lung machine but separated from the cardiopulmonary bypass circuit (Fig 1). Two segments of the study vein graft with a length of about $2 \mathrm{~cm}$ harvested by means of the no-

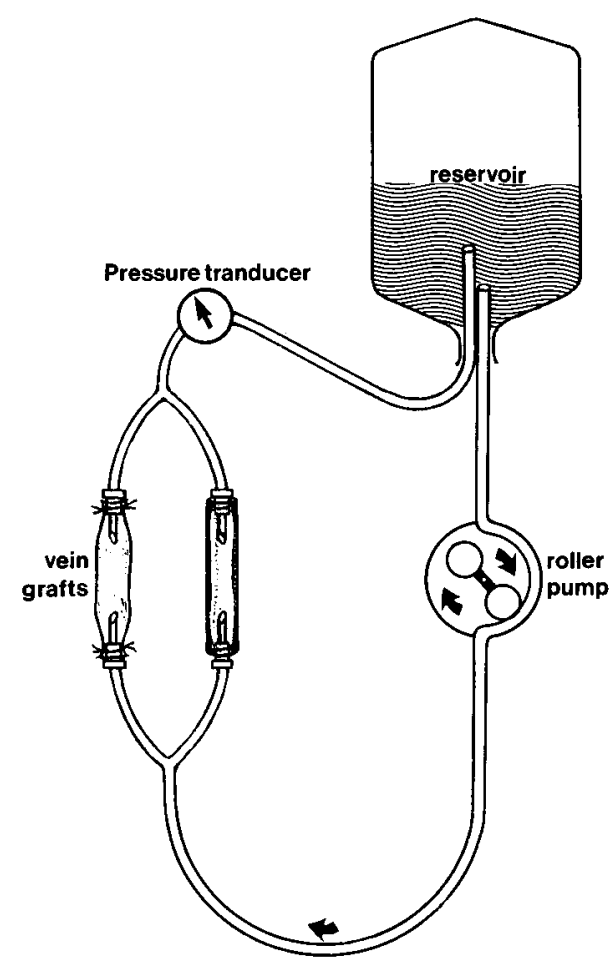

Fig 1. Schematic drawing of perfusion model.

touch technique were placed in the circuit and perfused for 60 minutes at the most. Perfusion pressure was the same as the pressure maintained in the patients (about $60 \mathrm{~mm} \mathrm{Hg}$ ) by adjusting the flow. At no point in the harvesting procedure was distention allowed before perfusion in the perfusion system. Specimens for histologic and immunohistochemical examination were taken before the start of perfusion $(t=0)$. One segment was taken out of the circuit after 30 minutes and the other after 60 minutes of perfusion to document possible early vessel wall changes in time. In this way 7 segments after 30 minutes and 7 segments after 60 minutes of perfusion were evaluated. We also evaluated 7 study vein graft segments with and 7 without a perivenous PTFE stent, ${ }^{*}$ again after 60 minutes of perfusion, by using the same setup. The PTFE grafts were sized for nonrestrictive support before the vein segments were placed in the perfusion circuit. In all cases this resulted in a 5-, 6-, or 7mm PTFE graft.

To evaluate the covering of the luminal surface of the study vein grafts with endothelium with an intact barrier function, Evans blue dye ${ }^{23}$ was added to the perfusion circuit during the last 5 minutes of perfusion. The Evans blue dye forms a complex immediately with albumin in the perfusate and stains the parts of the vessel in which the endothelial barrier is impaired. After perfusion, the vein grafts were divided in parts for morphologic examination or electron microscopy and frozen section. All specimens for morphologic analysis were taken some

${ }^{*}$ Grafts provided by W. L. Gore \& Associates, Inc, Flagstaff, Ariz. 
Table I. Qualitative classification of electron microscopic criteria for injury in human saphenous vein grafts

\begin{tabular}{lcccc}
\hline Degree of injury & Cell loss & Edema & Fragmentation of collagen & Thinning of cell structures \\
\hline Severe injury & Yes & Yes & Yes & No \\
Slight-to-moderate injury & No & Yes & No & Yes \\
No injury & No & No & No & No \\
\hline
\end{tabular}

Only evident changes are mentioned.

Table II. Degree of injury in different vein graft wall layers

\begin{tabular}{llll}
\hline Layer & Control & With support & Without support \\
\hline Endothelial layer-internal lamina & No injury & No to slight injury & Severe injury \\
Longitudinal muscle layer & No injury & No injury & Moderate injury \\
Circular muscle layer & No injury & No injury & Severe injury \\
Adventitial layer & No injury & No injury & Moderate injury \\
\hline
\end{tabular}

distance from either cannulation site to ensure that the segments were free of trauma caused by ligation or injury from possible flow disturbances at the cannula tip.

Immunohistochemistry. The pieces of the vein wall were partly fixed in formaldehyde and embedded in low melting point paraffin wax. Parts were also stored at $-196^{\circ} \mathrm{C}$ (liquid nitrogen).

Transverse sections of formaldehyde-embedded tissue samples were cut at $5 \mu \mathrm{m}$ and were stained with hematoxylineosin and elastica van Giesson stains. For immunohistochemistry, endogenous peroxidase activity was blocked by $0.3 \%$ (vol/vol) $\mathrm{H}_{2} \mathrm{O}_{2}$ in methanol. After preincubation with normal rabbit serum (Dakopatts A/S, Stockholm, Sweden) for 15 minutes (1:50 phosphate-buffered saline solution [PBS]/bovine serum albumin), the slides were incubated with the antibody CD31 (1:40 PBS-bovine serum albumin, Dakopatts A/S) for 60 minutes.

For formaldehyde-embedded tissue, slides, and cryostat sections, the method of staining was an indirect immunoperoxidase method with peroxidase-conjugated rabbit antimouse immunoglobulins (1:25 PBS/bovine serum albumin, Dakopatts A/S). Bound peroxidase was developed with $4 \mathrm{mg}$ (wt/vol) 3,3-diaminobenzidine tetrahydrochloride and $0.02 \%$ (vol/vol) $\mathrm{H}_{2} \mathrm{O}_{2}$ in PBS. The slides were counterstained with hematoxylin-eosin and mounted.

Electron microscopy. The vein-wall pieces were fixed in $2 \%$ (vol/vol) glutaraldehyde for 30 minutes and 1.5\% (wt/vol) osmium tetroxide for 10 minutes, dehydrated with acetone, and embedded in Epon 812 fixative. Ultrathin sections were collected on 300-mesh Formavar-coated nickel grids. The sections were contrasted with uranyl acetate and lead citrate and examined in a JEOL 1200 EX electron microscope (JEOL AB, Sundbyberg, Sweden).

The percentage of endothelium left on the luminal surface was estimated under light microscopy by dividing the circumference of the vein segments in 12 parts and assessing the percentage of endothelium left in each part. The assessment was done by 2 investigators (W.S. and H.W.M.N.) blinded as to whether the vein graft had been stented.

Specimens for electron microscopic examination were taken before the start of perfusion $(t=0)$ and after 60 minutes of perfusion to document possible early changes in the media.

At multiple sites of each vein, electron microscopic pictures were made of the whole vessel wall (from the endothelial layer up to the adventitial layer). The vessel wall was divided into 4 sections (intima, longitudinal muscle layer media, circular muscle layer media, and adventitial layer). Every section was assessed independently by 3 investigators (W.S., H.W.M.N., and A.B.) according to previous criteria. ${ }^{24}$ Subsequently, a qualitative assessment was made on behalf of the evident changes. These criteria are enumerated according to the classification mentioned in Table I.

Statistics. Data are expressed as the mean \pm SD. Groups were compared with the Student $t$ test.

\section{Results}

Quantifications of the vessel specimens with intact endothelium before and after perfusion are summarized in Fig 2. In all 14 vein graft segments, a normal endothelial layer was observed before the start of perfusion. In the 14 perfused specimens a progressive deendothelialization of $30 \%$ to $60 \%$ was perceived after 30 minutes of perfusion, culminating in almost complete de-endothelialization in 60 minutes (Fig 3). Loss of endothelial cells was observed with hematoxylineosin staining (Fig 3) and confirmed with CD31 staining (Fig 4). In 2 patients a CD $31^{+}$layer was seen at the intraluminal side after 60 minutes of perfusion, whereas no endothelial cells were found in hematoxylineosin staining. Electron microscopic examination showed in these specific cases a strong aggregation of thrombocytes to a denuded subendothelial matrix (Fig 


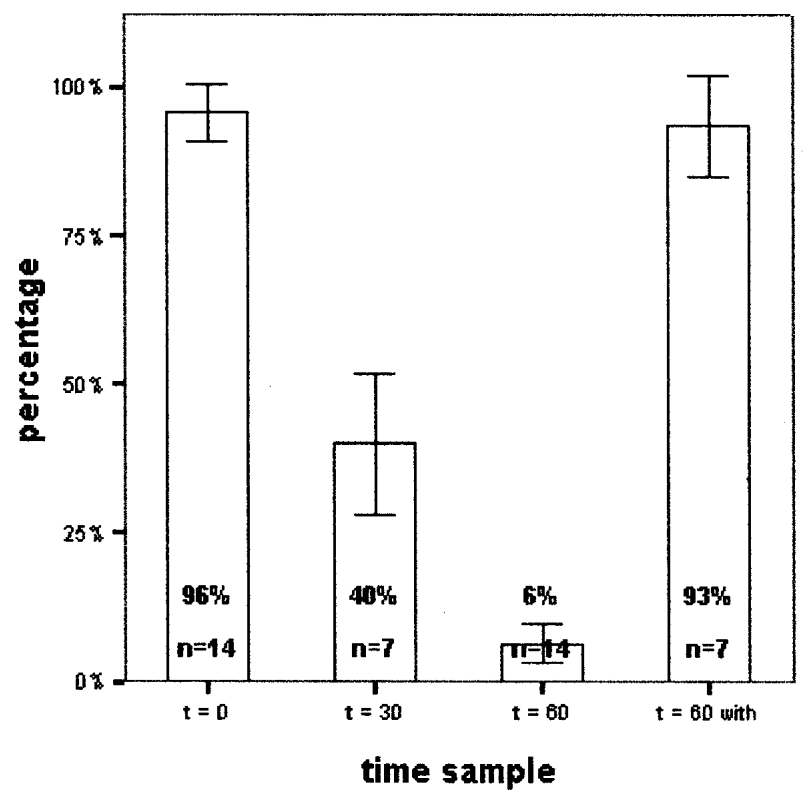

Fig 2. Endothelial coverage in vein graft specimens after different perfusion times. Nonstented (without support, $n=14$ ) and stented (with support, $\mathrm{n}=7$ ) vein specimens were perfused with whole blood, and endothelial coverage was quantified as described in the "Methods" section. $t=0$, Sample before perfusion; $t=30$, sample after 30 minutes of perfusion without support; $t=60$, sample after 60 minutes of perfusion without support; $t=60$ with, sample after 60 minutes of perfusion with perivenous support. Data are expressed as means \pm SD. Groups were compared with Student $t$ test. All groups were significantly different, with a $P$ value of less than .001 , except for group $t=0$ compared with group $t=60$ with.

5). No endothelial cells could be found in these specimens. To prevent overextension of the vessel during perfusion, 7 specimens were surrounded with a perivenous PTFE stent and compared with nonstented controls. An almost intact layer was found after perfusion (Fig 6), whereas the nonstented controls were devoid of endothelial cells. Electron microscopic examination of these vessel specimens confirmed the presence of endothelial cells in the stented grafts.

When Evans blue-albumin complex was added to the perfusate, the entire surface of the nonstented grafts displayed a blue color, indicating massive leakage of the complex into the vein wall (Fig 7, $A$ ). In the grafts with the perivenous stents, however, no Evans blue staining was observed, suggesting that the endothelial layer remained intact (Fig 7, B). The zones of deendothelialization at the extreme ends of the vein graft are probably caused by turbulence attributable to the tip of the cannula protruding into the vein graft lumen.
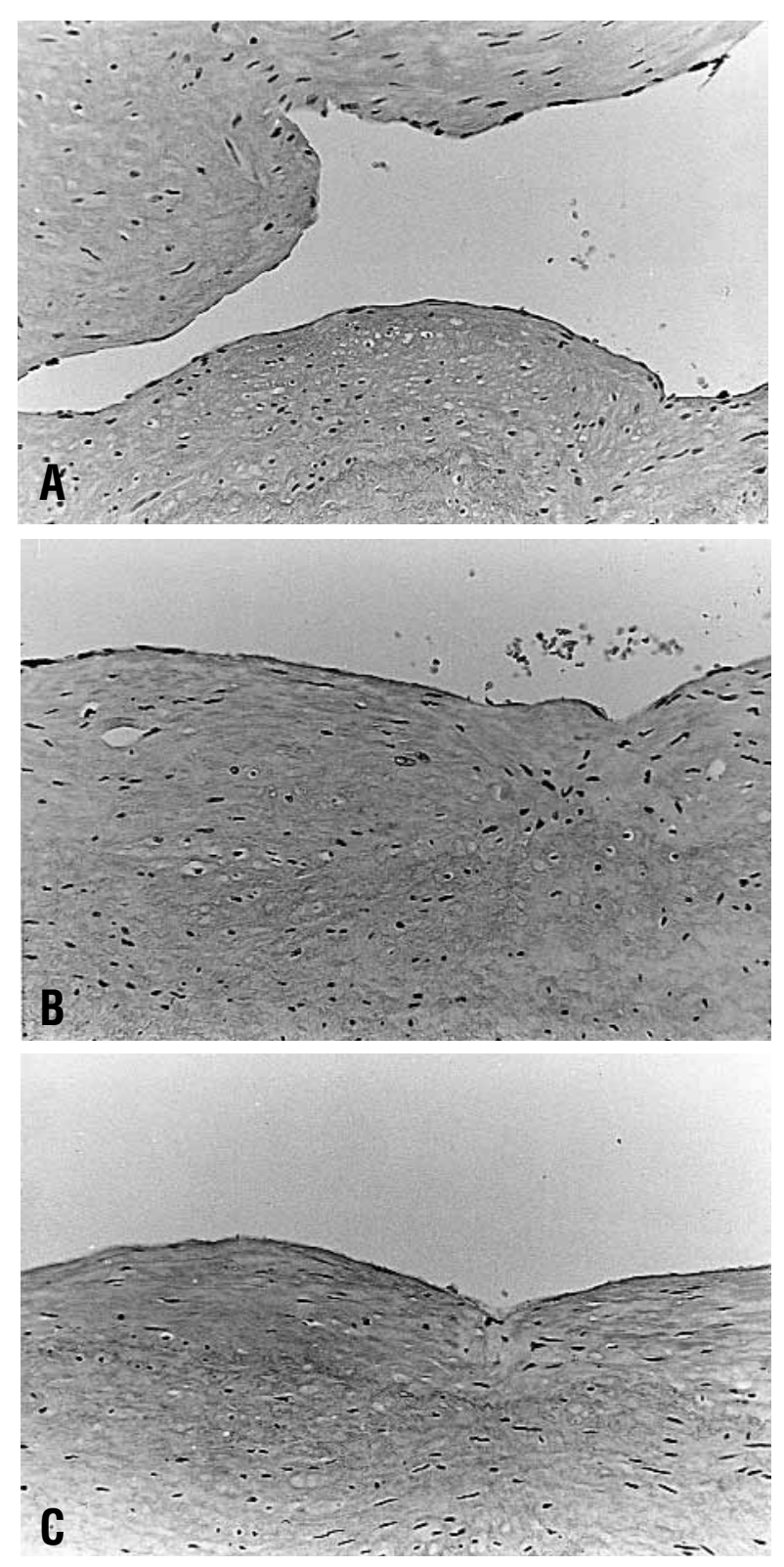

Fig 3. Endothelial coverage in vein specimens perfused for different time periods. A, Before perfusion, an intact endothelial layer is observed (hematoxylin-eosin staining). B, After 30 minutes of perfusion, large areas are devoid of endothelial cells. C, After 60 minutes of perfusion, a complete loss of endothelial cells is seen. Representative sections are shown. (Original magnification, 630×.)

The results of the electron microscopic study are shown in Table II. A severe injury pattern was shown in the endothelial layer-internal lamina layer, which is in agreement with the results obtained from light microscopy. 

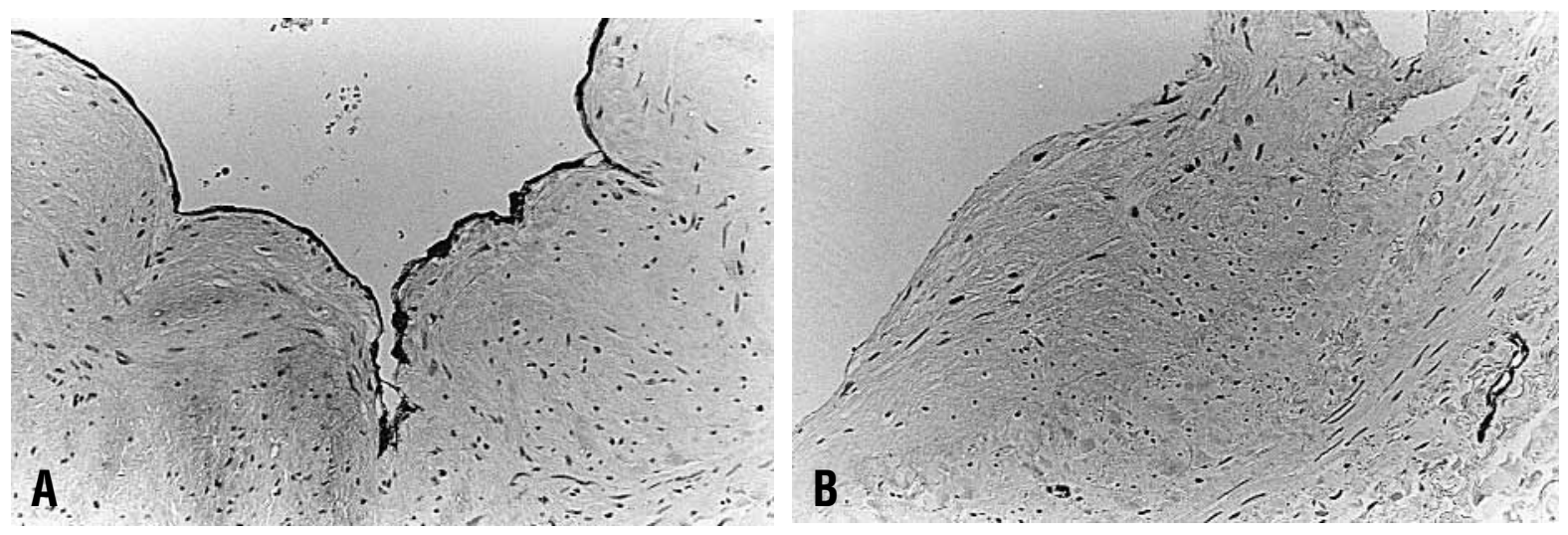

Fig 4. Endothelial coverage in vein specimens visualized with CD31 staining. (Original magnification, 630×.) A, Intact endothelium stains for CD31 at the start of perfusion. B, Absence of luminal CD31 staining after 60 minutes of perfusion, confirming complete endothelial cell loss. Note CD31 positivity in the vas vasorum.
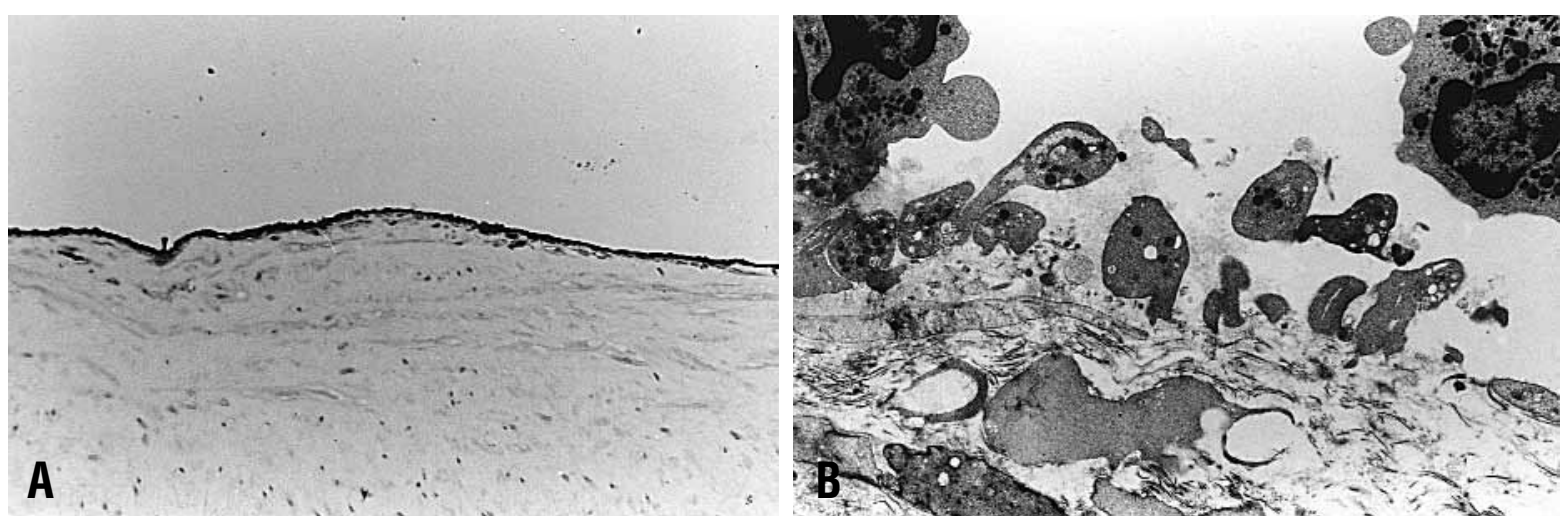

Fig 5. CD31 staining can reflect thrombocyte aggregation. A, Strong CD31 positivity after 60 minutes of perfusion, suggesting intact endothelial layer. (Original magnification, 630×.) B, Electron microscopic photomicrograph showing strong thrombocyte aggregation and no endothelial cells. (Original magnification, 7000×.)

There is a remarkable difference in injury seen in the circular layer of the media, which is subjected to the greatest strain, between the stented and the unstented group. In the stented vein grafts no injury was found in the smooth muscle cells of this layer, whereas in the unstented vein graft severe injury was found.

\section{Discussion}

Our study shows that perivenous support of human saphenous vein grafts exposed to arterial perfusion pressure in an extracorporeal circuit filled with autologous blood protects from otherwise severe damage caused by distention of the vein graft. This damage is characterized by de-endothelialization and rupture of media structures within 1 hour. The same picture was documented in animal experiments early after implantation. ${ }^{10,11}$ Therefore, benefit is to be expected also for perivenous support of a rather muscular vein, such as the greater saphenous vein, which is mostly used for grafting in human subjects. Moreover, in these animal experiments sequential time samples demonstrated that this damage leads to an inflammatory reaction in the first week, followed by intimal hyperplasia and media hypertrophy, resulting in extensive fibrosis of the vein graft wall with an irregular structure in 4 to 6 weeks. This is in contrast to the perivenous supported grafts, which show complete regeneration of the endothelial layer and gradual arterialization.

The de-endothelialization or even dysfunction of the overlying endothelium will result in adhesion and aggregation of thrombocytes to the subintimal layer and invasion of the media by leukocytes. By lack of down-regulation of the endothelial growth factors, cytokines and adhesion molecules are expressed in the media. This inflammatory reaction after de-endothelialization in the first week, as observed in both animals 

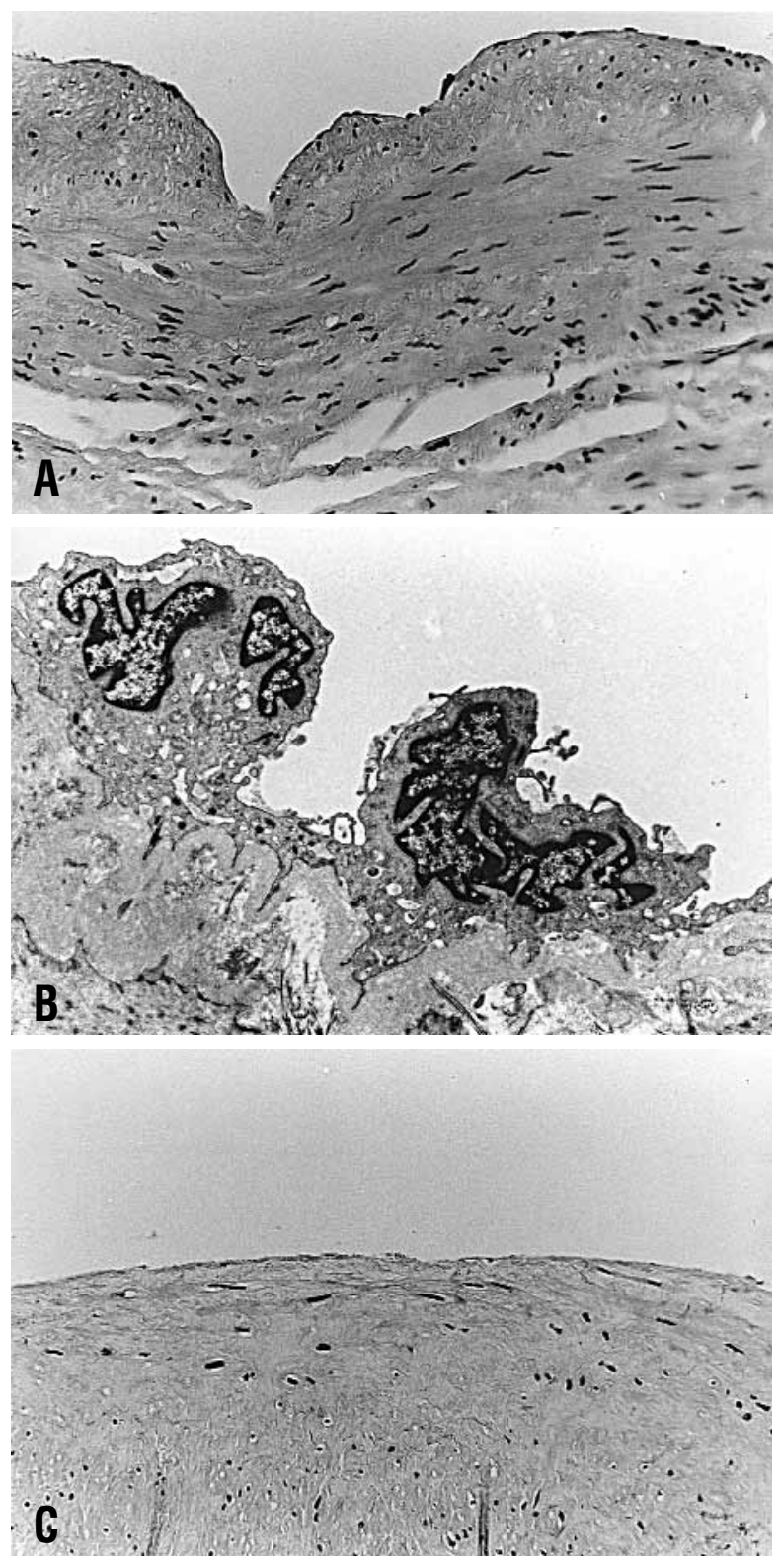

Fig 6. A, Cross section through a stented vein after 60 minutes of perfusion, showing an intact endothelial layer. (Original magnification, 630×.) B, Electron microscopic photomicrograph confirms the presence of endothelial cells after 60 minutes of perfusion. (Original magnification, 7000×.) $\mathbf{C}$, Unstented control vein showing no endothelium.

and human subjects, ${ }^{21}$ will promote proliferation of smooth muscle cells and atherosclerosis, leading to luminal obstruction. With no doubt, prevention of the injury in the first hour will have a favorable effect on graft wall integrity and, as a consequence, on patency in human subjects. Additionally, when the distention damage in the initial period is prevented by a perive-
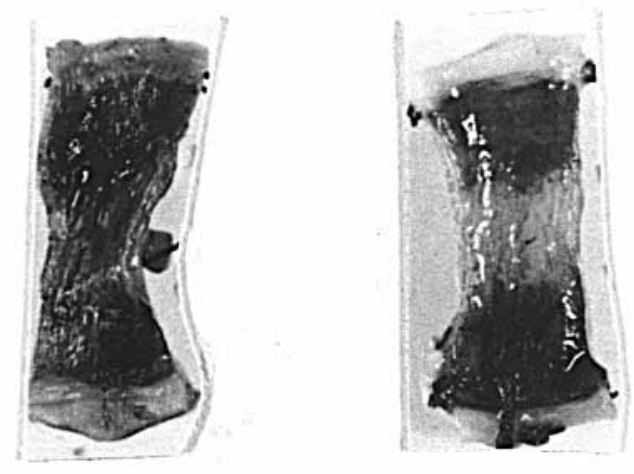

Fig 7. Vascular leakage as visualized with Evans blue dye. Evans blue dye was added to the whole blood that was perfused through the vein specimens. Left, Unstented graft showing no endothelial layer. Right, Stented graft showing intact endothelial layer. The zones of de-endothelialization at the end of the vein graft are due to turbulence attributed to the tip of the cannula protruding in the vein graft lumen.

nous support providing a more gradual adaptation to arterial pressure, a more physiologic medial thickening or arterialization ensues, promoting long-term patency, as in the animal models.

Our perfusion model is designed to mimic only the first hemodynamic and rheologic situation a venous graft will encounter after implantation while the patient is still undergoing bypass. Although the perfusion is nonpulsatile continuously, which is the same as in the clinical situation for only a short period after completion of the proximal anastomosis, we postulate that with pulsatile flow, caused by more serious overdistention, even more severe damage is to be expected.

For perivenous support, we used a PTFE graft because the material characteristics are not important in the early period as long as distention by the arterial pressure is prevented. However, we have to be aware that for adequate remodeling of the vein graft in the later period the material characteristics of perivenous support have to be more carefully selected. ${ }^{11,25,26}$

Our data in the first hour of whole blood perfusion show highly reproducible structural degradation in human vein grafts, which is similar to that seen in animal experiments and the postmortem study in patients by Kockx and associates. ${ }^{21}$ Furthermore, our data show that also in the human saphenous vein, these changes can be prevented by adequate perivenous support.

We tested the barrier function of the endothelium with Evans blue dye. In this way an instant assessment of the presence of an endothelial layer with an intact barrier function in the graft is possible. 
In preliminary studies we found fVIIIR.Ag/vWF positivity in the absence of endothelial cells, albeit more weekly. Therefore, we have chosen CD31 (platelet and endothelial cell adhesion molecule) to depict the endothelial layer. ${ }^{27}$ In most instances this was satisfactory, although we faced false positivity caused by platelet aggregation in 2 specimens in the absence of endothelial cells. Therefore, it is important to establish the presence of endothelial cell nuclei with hematoxylin-eosin stain also.

In this study, next to the electron microscopic confirmation of the beneficial effect of perivenous support on the endothelial layer and internal lamina, a remarkable attenuation of smooth muscle cell injury was found in the circular muscle layer of the supported vein graft wall. This seems to be rational because especially the circular layer will be prone to increased strain during overdistention. Although in the first hour of perfusion no specific inflammatory mediators, such as early genes or adhesion molecules, can be expected, we found adherence of leukocytes at the denuded subintimal layer in a few samples.

It is remarkable and in contrast to our findings that in an earlier study $^{28}$ no complete desquamation of endothelium was found in nonsupported human vein grafts that had been exposed to arterial perfusion pressure in a more or less comparable circuit. The main difference compared with our setup was that in this study Krebs solution was used as the perfusate. In preliminary experiments with Krebs solution in our model, we could reproduce these previous findings (unpublished results). An explanation of this observation might be that the Krebs solution results in different flow, pressure, and shear stress conditions compared with blood perfusion. More important in explaining the complete de-endothelialization could be the presence in blood of activated enzymes or proteases capable of destroying the natural endothelial cell connections. Perfusion with autologous blood might therefore mimic the clinical situation more accurately.

In conclusion, in our in vitro closed-loop blood perfusion model, reproducible vessel wall changes were observed in the rather muscular human vein graft specimens exposed to arterial pressure, showing complete de-endothelialization and severe disruption of the circular muscle layer of the media after 60 minutes of perfusion. These destructive changes could be prevented with perivenous support preventing overdistention caused by the arterial pressure.

We thank E. K. Jansen, MD, for the statistical assessment.

\section{REFERENCES}

1. Fitzgibbon GM, Kafka HP, Leach AJ, Keon WJ, Hooper GD, Burton JR. Coronary bypass graft fate and patient outcome: angiographic follow-up of 5,065 grafts related to survival and reoperation in 1,388 patients during 25 years. J Am Coll Cardiol 1996;28:616-26.

2. Cameron A, Davis KB, Green G, Schaff HV. Coronary bypass surgery with internal thoracic artery grafts-effects on survival over a 15 year period. N Engl J Med 1996;334:216-9.

3. Peck WP, Orszulak TA, Anderson BJ, Schaff HV. Single versus bilateral internal mammary artery grafts: 10-year outcome analysis. Ann Thorac Surg 1997;64:599-605.

4. Sergeant PT, Blackstone EH, Meyns BP. Does arterial revascularization decrease the risk of infarction after coronary artery bypass grafting? Ann Thorac Surg 1998;66:1-11.

5. Barner HB. Arterial grafting: techniques and conduits. Ann Thorac Surg 1998;66:S2-5.

6. Grandjean JG, Boonstra PW, Den Heyer P, Ebels T. Arterial revascularization with the right gastroepeiploic artery and internal mammary arteries in 300 patients. J Thorac Cardiovasc Surg 1994;107:1309-16.

7. Chen AH, Nakao T, Brodman RF, et al. Early postoperative angiographic assessment of radial artery grafts used for coronary artery bypass grafting. J Thorac Cardiovasc Surg 1996;111:120812.

8. van der Meer J, Hillege HL, Kootstra GJ, et al. Prevention of oneyear vein graft occlusion after aortocoronary bypass surgery: a comparison of low-dose aspirin, low-dose aspirin plus dipyridamole and oral anticoaglulants. Lancet 1993;342:257-64.

9. Barra JA, Volant A, Leroy JP, et al. Constrictive perivenous mesh prosthesis for preservation of vein integrity: experimental results and application for coronary bypass grafting. J Thorac Cardiovasc Surg 1986;92:330-6.

10. Hinrichs WLJ, Zweep H-P, Satoh S, Feijen J, Wildevuur CRH. Supporting, microporous, elastomeric, degradable prostheses to improve the arterialization of autologous vein grafts. Biomaterials 1994;15:83-91.

11. Zweep HP, Satoh S, van der Lei B, et al. Autologous vein supported with a biodegradable prosthesis for arterial grafting. Ann Thorac Surg 1993;55:427-33.

12. Mehta D, George SJ, Jeremy JY, et al. External stenting reduces long-term medial and neointimal thickening and platelet derived growth factor expression in a pig model of arteriovenous bypass grafting. Nat Med 1998;4:235-9.

13. Bambang LS, Moczar M, Lecerf L, Loisance D. External biodegradable supporting conduit protects endothelium in vein graft in arterial interposition. Int J Artif Organs 1997;20:397-406.

14. Stansby G. Vein quality in vascular surgery. Lancet 1998;351:1001-2.

15. Cox JL, Chiasson DA, Gotlieb AI. Stranger in a strange land: the pathogenesis of saphenous vein graft stenosis with emphasis on structural and functional differences between veins and arteries. Prog Cardiovasc Dis 1991;34:45-68.

16. Schaeffer U, Tanner B, Strohschneider T, Stadtmüller A, Hannekum A. Damage to arterial and venous endothelial cells in bypass grafts induced by several solutions used in bypass surgery. Thorac Cardiovasc Surg 1997;45:168-71.

17. Cavallari N, Abebe W, Mingoli A, et al. Short-term preservation of autogenous vein grafts: effectiveness of University of Wisconsin solution. Surgery 1997;121:64-71.

18. Angelini GD, Newby AC. The future of saphenous vein as a coronary artery bypass conduit. Eur Heart J 1989;10:273-80. 
19. Motwani JG, Topol EJ. Aortocoronary saphenous vein graft disease: pathogenesis, predisposition, and prevention. Circulation 1998;97:916-31.

20. Nwasokwa ON. Coronary artery bypass graft disease. Ann Intern Med 195;123:528-45.

21. Kockx MM, Cabier BA, Bortier HE, De Meyer GR, Van Cauwelaert PhA. The modulation of smooth muscle cell phenotype is an early event in human aorto-coronary saphenous vein grafts. Virchows Arch 1992;420:155-62.

22. Lerner RG, Moggio RA, Reed GE. Endothelial loss due to leukocytes in canine experimental vein-to-artery grafts. Blood Vessels 1986;23:173-82.

23. Barone GW, Farley PC, Conerly JM, Flanagan TL, Kron IL. Morphological and functional techniques for assessing endothelial integrity: the use of Evans blue dye, silver stains, and endothelial derived relaxing factor. J Card Surg 1989;4:140-8.
24. Papadinotrion JM. Diagnostic ultrastructure of non neoplastic diseases. London: Churchill Livingstone; 1992.

25. Izzat BA, Dheeraj M, Bryan AJ, Reeves B, Newby AC, Angelini GD. Influence of external stent size on early medial and neointimal thickening in a pig model of saphenous vein bypass grafting. Circulation 1996;94:1741-5.

26. De Meyer GRY, Van Put DMJ, Kockx MM, et al. Possible mechanisms of collar-induced intimal thickening. Arterioscler Thromb Vasc Biol 1997;17:1924-30.

27. Newman PJ. The biology of PECAM-1. J Clin Invest 1997;99:3-8.

28. Golledge J, Turner RJ, Harley SL, Springall DR, Powell JT. Development of an in vitro model to study the response of saphenous vein endothelium to pulsatile arterial flow and circumferential deformation. Eur J Vasc Endovasc Surg 1997;13:605-12.

Access to The Journal of Thoracic and Cardiovascular Surgery Online is reserved for print subscribers!

Full-text access to The Journal of Thoracic and Cardiovascular Surgery Online is available for all print subscribers. To activate your individual online subscription, please visit The Journal of Thoracic and Cardiovascular Surgery Online, point your browser to http://www.mosby.com/jtcvs, follow the prompts to activate your online access, and follow the instructions. To activate your account, you will need your subscriber account number, which you can find on your mailing label (note: the number of digits in your subscriber account number varies from 6 to 10). See the example below in which the subscriber account number has been circled:

\section{Sample mailing label}

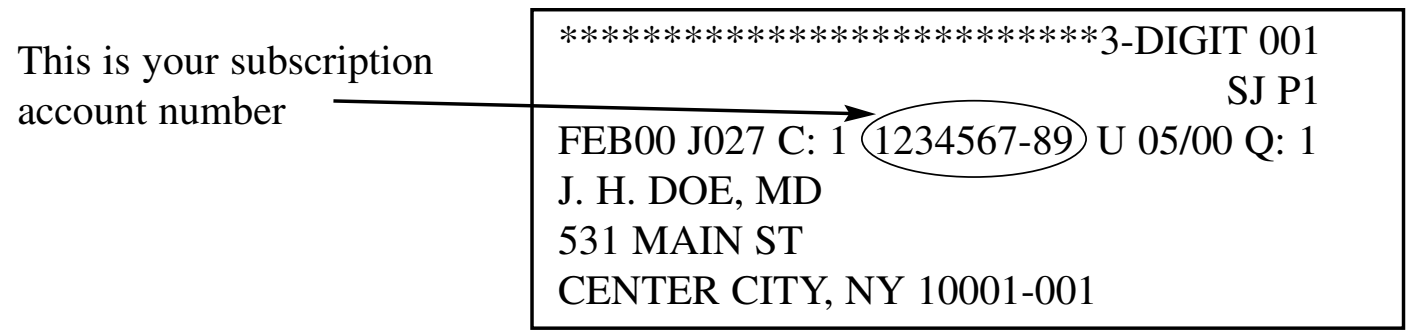

Personal subscriptions to The Journal of Thoracic and Cardiovascular Surgery Online are for individual use only and may not be transferred. Use of The Journal of Thoracic and Cardiovascular Surgery Online is subject to agreement to the terms and conditions as indicated online. 